\title{
REVIEW
}

\section{A Practical Review of Mastery Learning}

\author{
Marshall Winget, ${ }^{\mathrm{a}}$ Adam M. Persky, PhD ${ }^{\mathrm{a}, \mathrm{b}}$ \\ ${ }^{a}$ University of North Carolina at Chapel Hill, UNC Eshelman School of Pharmacy, Chapel Hill, North Carolina \\ ${ }^{\mathrm{b}}$ Associate Editor, American Journal of Pharmaceutical Education, Arlington, Virginia
}

Corresponding Author: Adam M. Persky, University of North Carolina at Chapel Hill, Eshelman School of Pharmacy, 325 Beard Hall, CB\#7569, Chapel Hill, NC 27599. Tel: 919-966-9104. Email: apersky@unc.edu

Submitted October 3, 2021; accepted January 10, 2022; ePublished January 2022

Objective. To review mastery learning and provide recommendations for implementation in a competency-based curriculum

Findings. Mastery learning was introduced in the 1960s. Its goal is to ensure all students reach a desired level of mastery or competency. In this model, students acquire knowledge, skills or attitudes, complete formative assessments on that learning and if they achieve the desired level, can proceed to enrichment activities. Students who do not meet the desired level of mastery, proceed through corrective activities and retest. Evidence suggests students within a mastery learning model perform better academically than non-mastery models with moderate effect sizes. There are several theoretical reasons why mastery learning can result in better performance including aspects of motivation, testing and feedback. Conclusion. We make several recommendations on how to modernize mastery learning for the pharmacy education classroom including the use of more cumulative testing and assessment of baseline knowledge and skills. In addition, models of successive relearning may be applied to this model.

Keywords: mastery learning; competency-based education; successive relearning; remediation; outcomes-based education

\section{INTRODUCTION}

\section{Competency-based curriculum}

Competency-based curriculum is a type of outcome-based education that focuses on abilities of the student to do job-related tasks, promoting learner-centeredness, and de-emphasizing time-based training. ${ }^{1}$ The continual movement towards competency-based education in the health sciences brings new tenets. The first is the graduate should be competent in a diversity of abilities across various domains and a variety of contexts.

Competency is the observable ability of the pharmacist to integrate their knowledge, skills, values, and attitudes. ${ }^{2}$ Being competent means the learner possesses the required abilities in all domains in a certain context at a defined stage of pharmacy education or practice. Thus, competency-based education balances curricular structure with opportunity (eg, just-in-time learning) and time-based learning (eg, everyone proceeds at the same pace through a curriculum) with flexibility (eg, students proceed at their own pace). One instantiation of competency-based education is the mastery learning model. The mastery learning model can balance time-based learning with flexibility because of its corrective pathways. It also can balance structured learning with more opportunistic learning.

\section{Mastery Learning Overview}

In the 1960 s, Bloom determined that the most efficacious learning situation was one-on-one tutoring. ${ }^{3}$ One-onone tutoring starts with the student gaining an understanding of material and after that acquisition, their understanding is assessed through a formative assessment. If there is a concept that is unclear to the student, the teacher or tutor provides feedback and exercises to enhance understanding (ie, corrective activities). Only when the student demonstrates adequate knowledge of the content (ie, mastery), does the teacher or tutor present new material and the student can move on to other material. Thus, each student would move through the learning sequence at their own rates depending on how quickly they acquire the desired knowledge or skills. If this model of instruction is the most efficacious, then the challenge to instructors and curricular designers is to find practical ways to better meet individual learning needs in a group-based classroom. The concept of "mastery learning" attempts to tackle this challenge.

Mastery learning's goal is for all, or nearly all, students to "master" or become competent in the course material. "Mastery" and the learning outcomes for students must be well-defined by the instructor for the system to be successful. Each topic or grouping of topics (eg, instructional units) organize learning outcomes into one- or two-week intervals and the structure of these units are displayed in Figure 1. Following the initial instructional period, students complete a 
formative assessment based on the established learning outcomes. For students who accomplish the predefined level of mastery, enrichment activities are offered to supplement the students' understanding of the material. Conversely, students who do not accomplish the predefined level of mastery are given corrective exercises specific to the concepts missed by the student. These students are then given a separate formative assessment, pertaining to the same learning outcomes, and must demonstrate mastery prior to moving to the next unit. That is, students who do not accomplish mastery the first time, are remediated until they demonstrate mastery.

As mentioned, there are several steps to the mastery learning: initial learning, formative assessment; corrective activities; and enrichment activities. ${ }^{4}$ The first step is to specify learning goals or objectives. Next is developing formative assessments. The third step is organizing corrective activities which is followed by planning enrichment activities. The final step is developing summative assessments.

In the first step, specifying learning goals or objectives, instructors make judgements on what new concepts, knowledge or skills are important for all students to learn well. This also involves deciding at what level students should be able to accomplish these goals, whether it is simple recall or applying new or different skills to a problem, or synthesizing information. These learning objectives can be constructed with the SMART objective (specific, measurable, achievable, realistic, and timely) or the Mager model. ${ }^{5,6}$ The Mager model includes the minimum acceptable performance and the context for that performance. ${ }^{5}$ As a comparison, a SMART objective may be, "By the end of this lesson, the student will be able to predict the changes in drug concentration given changes in clearance and volume of distribution." The same objective in the Mager model would be "Given an open-ended patient case, the student must be able to predict how drug concentrations will change in response to changes in clearance and volume of distribution with the acceptable level of performance as $80 \%$ correct." The Mager model may be favored in competency-based education as it defines the minimal standard or level of mastery (see Recommendations).

The second step of designing mastery learning is the formative assessments. This assessment provides students with feedback on their progress towards achieving the learning outcomes. ${ }^{7-9}$ The goal is to correct any learning difficulties (eg, errors, misunderstandings) from instruction and direct future study. These can be any format but should align with the learning objectives in terms of complexity and format. ${ }^{4,9}$ That is, there should be instructional alignment in that, if the learning objective is for an open-ended assessment that is focused on application of knowledge, then the formative assessments should be open-ended and focused on application of knowledge. ${ }^{10,11}$ The next part of the formative assessment is setting the standard for mastery. While there many methods for standard setting (eg, Angoff), most use a simple percentage. ${ }^{4}$ The literature recommends this standard be no lower than what may constitute a "B" or $80 \%$ or no higher than $90 \%$, unless the task is so critical that it needs to be demonstrated at a high level (eg, patient safety). ${ }^{4}$ Finally, the last part is to create a second, parallel formative assessment that measures the same objectives of the first assessment, with the same standards, but whose questions may vary in structure or format. ${ }^{4,9}$ This second assessment is used to check for success after corrective activities. For the formative assessments, and the summative, using blueprinting strategies can help with assessment consistency (see Recommendations section).

The next step is feedback and corrective activities. Because feedback provides insight on what the learner has mastered or done well and identified areas for improvement, good feedback also provides direction on how a student can get better at these latter areas. ${ }^{7,12,13}$ The corrective activities must be a different type of engagement consistent with the literature on remediation. ${ }^{14,15}$ That is, if students learned the topic initially by reading, asking them to correct their knowledge with re-reading is pointless. After students engage with the corrective activities, they can take the second formative assessment.

If students achieve the desired level of mastery on the first attempt, they can engage in enrichment activities. These activities should be rewarding and challenging to optimize motivation (see Theoretical Section). ${ }^{4}$ It also may be prudent to allow all students, especially earlier in the semester, to engage in these enrichment activities to motivate students to do well in future units. ${ }^{4,9}$ The enrichment activities can be made available to all students. In some cases, enrichment activities can be used for extra credit to incentivize completion.

The final step is developing the summative assessment. Per best practices, this assessment should be aligned with the learning objectives, formative assessments, and all instructional activities. Again, this can be part of the overall blueprint for assessment. Summative assessments determine the grade for the unit or course and would be appropriate to use more traditional grading (eg, $\mathrm{A}=90 \%$ ). All assessments are criterion-based,aligned with the learning objective, and ensurei adequate sampling of these objectives.

Finally, the mastery approach requires the assignment of grades. The mastery learning lends itself to a Pass / Fail grading system and Guskey recommended an Honors, Pass, Fail system because it does not reward poor work but acknowledges going above and beyond expectations. ${ }^{4}$ Although, mastery learning can be adapted to other grading systems, the grading system still relies on matching the level of competency (achievement of outcomes) to the grade and does not reward things like participation. ${ }^{16-18}$ Deciding what is mastery or competency can be complex. For example, 
mastery or competency can be based on the amount of learning outcomes achieved (eg, competent on $80 \%$ of learning outcomes) or it can be based on mastering or being competent on each learning outcome as a set level (achieve an $80 \%$ correct on each learning outcome).

In summary, mastery learning stresses five things. ${ }^{4}$ The first is students will be graded solely based on their performance on the (final) summative assessment. Second, the student will be assessed on predetermined standards and not relative to peers. Third, students who attain the standard will receive the appropriate grade reward. Fourth, throughout learning the student will be given a series of ungraded, diagnostic assessments to promote and pace learning. And finally, each student will be given all the help they need to learn.

\section{Evidence for Mastery Learning Effects}

Various studies have been conducted to compare Mastery Learning to other instructional strategies.. Collectively, the literature supports mastery learning in terms of improved student achievement, final examination scores, attitude toward learning and content, and less variation in student performance. ${ }^{19-23}$ A meta-analysis of 36 mastery learning studies demonstrated an average effect size of 0.59 , a medium-large effect. ${ }^{20}$ These effect sizes varied based on the properties of the courses. For example, courses with a higher "mastery threshold" had a larger effect size in terms of increasing student examination scores. Other differences that impact effect size include subject matter, locally developed tests (vs. nationally standardized), pace of the course, and extent of feedback. To note, one meta-analysis included comparisons to studies using Keller's Personalized System of Instruction (PSI) and in general, the mastery learning model demonstrated greater effect sizes. ${ }^{20}$ Keller's PSI represents a system used in one-on-one tutoring. ${ }^{24}$

Whiting and colleagues showed an improvement in GPA by almost one and one-half grades (eg C to a B+) in classes taught by mastery learning $(n=7,179) .{ }^{3}$ Average grades in classes taught by mastery learning ranged from $97 \%$ to $99 \%$ with only $1.5 \%(\mathrm{n}=108)$ of students achieving a grade of $\mathrm{F}$. A study by Marshall supported these findings with a $10 \%$ increase in average semester grade between the mastery learning course and the traditional course. ${ }^{21}$ This study also showed a reduction in formative assessment attempts throughout the course, demonstrating that students become more efficient at learning. Although difficult to quantify, Marshall also demonstrated the positive affective impact of mastery learning by comparing the perceived school climate and culture between students in a mastery learning course compared to those in a traditional course. ${ }^{21}$

\section{Theoretical underpinnings of Mastery Learning}

Although evidence demonstrates that mastery learning is beneficial in a myriad of ways; there are many potential reasons why it works well. The theoretical underpinnings include: creating a motivational environment, regular opportunities for retrieval practice, and a focus on feedback. The following section briefly reviews the theoretical underpinnings of the mastery learning model.

One overarching theme in mastery learning is establishing an environment that supports motivation. The selfdetermination theory (SDT) of motivation has threes aspects: autonomy, competence, and relatedness. ${ }^{25,26}$ Autonomy is the freedom to choose and the idea that, when an individual has a choice, motivation increases. The autonomy aspect is present in mastery learning through the corrective activities, choice of completing enrichment activities, and the timelimits of learning. As an example, in the ideal mastery learning model, there is a choice of corrective activities allowing the struggling student to feel motivated. The student also has a choice whether they want to complete enrichment activities. And maybe most importantly, the flexibility in time allows an opportunity for choice as well - the student has some flexibility to self-pace their learning and spend more time on areas for weakness and less time on areas of strength. The second aspect of SDT is competence. Here, mastery learning is clear that the goal is to build competence. Again, for the struggling student, there is a pathway for competence despite initial poor performance. In theory, this could motivate students who may not think that would be able to "compete" for a grade otherwise. In contrast, mastery learning does not "let students off the hook" in the same way that traditional instruction does. In traditional instruction if a student does not complete an assignment, they would be assigned a failing grade; whereas in a mastery learning course, students would receive an incomplete grade until the student can complete the assignment. Finally, relatedness can be seen in the instructional activities and the enrichment activities. In the normal classroom, often the higher achieving students may not be challenged to go "above and beyond". For students who have demonstrated mastery of the unit content, offering enrichment activities allow for continued practice and unique ways to reinforce mastery of the learning objectives. Thus, the assessments and enrichment activities can be motivating if they are designed to help support the students' understanding of how the knowledge, skills and attitudes help them as a future pharmacist. With the focus on goals related to the practice of pharmacy, this has positive effects on achievement and motivation. ${ }^{27,28}$

While motivation is a large part of the mastery learning model, mastery learning also focuses on retrieval practice (ie, testing effect). At the end of each unit of instruction is a formative assessment and it is well documented these 
assessments are beneficial in the because of their ability to provide feedback. ${ }^{7,8}$ However, these formative assessments allow students to apply what they learned and serves as a retrieval opportunity, both which improve learning and metacognition. ${ }^{29,30}$ For example, when students study a topic and are provide an opportunity to re-study the material or retrieve information (eg, complete an assessment), the students that retrieve information have better retention of material with medium to large effect sizes. ${ }^{30}$

Finally, the mastery model provides for repeated feedback. Feedback is an essential strategy for learning leading to large effect sizes. ${ }^{31}$ In the mastery model, feedback is provided at each step, usually tied to an assessment. Explicit feedback given in mastery learning courses allow the teacher to "prescribe" corrective exercises specific to each student's learning situation. This minimizes the attention given to less necessary topics that students may have already mastered.

\section{Recommendations and Implementation Strategies for Mastery Learning}

Table 2 summarizes recommendations for implementing mastery learning. Mastery learning has stemmed from primary and secondary education and the cycle of topic acquisition to corrective activities and enrichment activities being effectively used in a single class period. ${ }^{4}$ In the authors' view, this microcycle can be applied to the health-professions classroom, however, a potential longer, macrocycle may be better suited for a competency-based curriculum. As a recommendation, the macrocycle may take days to weeks. (Figure 2) One of the challenges in the mastery learning model is that mastery of a topic, traditionally, prevents students from moving on to the next topic. This may not be completely feasible in the classroom setting. Regardless, stop points can be implemented and students still have to ability to self-pace, achieving competency at their own rate.

Mastery learning could be very adaptable to the model of successive relearning. In successive relearning, students practice to-be-learned content until a designated level of mastery is achieved in each of multiple practice sessions (ideally three to four different study sessions). ${ }^{32-35}$ That is, a student would reach a mastery threshold on Day 1 and then again must obtain that level on subsequent study days. This can be incorporated into the mastery learning model because of the frequency of assessments. Thus, each mastery unit should include older material and assessment should be cumulative (see later in this section and Table 2 for an example of quizzes, spacing and blueprinting). Successive relearning, especially for conceptual material, has large effect sizes when measured by long-term retention. ${ }^{33}$ Therefore, it may not be necessary to have high levels of initial learning (eg, high initial competency thresholds) because if the course is built to be more cumulative and students must relearn material throughout, those initial mastery levels can be low because the additional spacing will supersede the initial levels of learning. ${ }^{34}$ Courses that want to maximize retention should avoid spending time and effort on learning to a high initial criterion (greater than 90\%) but should instead devote those resources to subsequent relearning sessions.

Another addition to modernize the mastery model is to activate prior knowledge through baseline testing or activities. Some proponents of mastery learning promote baseline assessment of knowledge and skills. ${ }^{36}$ This suggestion would be in line with the literature on the importance of prior knowledge being the basis for new learning. As such, bringing that baseline understanding into light can help customize the learning experience. ${ }^{37,38}$ Before each unit, a baseline test can help provide feedback on areas the student can focus on for the upcoming unit and reactivate prior knowledge; this can be done with multiple-choice testing. ${ }^{39-41}$

After a baseline assessment, the first traditional part of mastery learning is the acquisition of knowledge, skills, values, and attitudes. In the mastery learning model there is no specific guidance on how this occurs and as such we can rely on current best practices. For knowledge acquisition, part of the strategy may be self-directed learning or guided selfpaced instruction as it may be most cost-effective as it can be more efficient. ${ }^{42}$ This can be combined with peer-to-peer interaction (collaborative learning, peer instruction, cooperative learning) where students can discuss and generate their own understanding. Peer-to-peer instruction can help facilitate the application of knowledge, skill development, or the development of values and attitudes. Peer-to-peer instruction has a large effect size in meta-analysis ${ }^{43,44}$

During this acquisition phase, we can also apply components of retrieval and spacing like successive relearning. In the successive relearning model, students can test themselves on these key concepts and when correct, can remove them from their study session. ${ }^{35}$ Then the next session, they retest the new and old concepts and again, when they correctly solve the problem or remember the key concept, they can drop it and repeat the cycle at some later time.

The last part of the acquisition phase can include opportunities for students to get questions answered from instructors or experts for the concepts that are still unclear. During this process, the key position is the corrective feedback and modeling the thought process.

The formative assessment's goal is to manage learning. ${ }^{9}$ As such, these assessments occur in short intervals. After a topic is sufficiently learned, the formative assessment takes place and is a check to make sure students are making progress as students practice. This assessment should be no or low stakes. As with any assessment, it should be appropriately blueprinted to ensure adequate sampling of the competencies (Table 1). ${ }^{45}$ Blueprinting would also help with 
any retesting to ensure consistency in assessing the learning objectives. The use of software packages (eg, ExamSoft) may facilitate the tagging of questions and allow for easier topic-level feedback. The threshold for this assessment should be high enough where the instructor feels students have learned enough to move on successfully but not too high as to make it unreasonable. We also recommend having these assessments being cumulative (see prior discussion on successive relearning).

Students who do not successfully achieve mastery after the first formative assessment should be given prescriptive feedback. Strong feedback is based on observable task, is highly specific, based on astandards. ${ }^{46}$ Feedback is most beneficial when it is provided for incorrect answers than correct answers, for correct answers when feedback is delayed, or correct answers when they are made with low confidence. ${ }^{31}$ Feedback should be tied to specific learning objectives to ensure corrective activities are tailored to a student's situation. General feedback, for example, a percent score, is not helpful in diagnosing individual learning difficulties, and prescribing remediation procedures. ${ }^{3}$ Thus feedback needs to be specific. This feedback can be automated to some degree through most learning management software. Correction needs to involve strategies that differ from the original means of study. ${ }^{4}$ Like the acquisition phase, various strategies can be used such as self-explanation or instructional explaining or other methods that reduce misconceptions. ${ }^{47-49}$

In the area of re-testing, the recommendations are to maintain the same blueprint as the original assessment. The timing of re-testing may vary based on the time it takes students to study the material to pass. One strategy may be to include re-testing material on future quizzes. The advantage is there is no need to have additional testing time, the downside is the remediation session overlaps with the new learning session which would be an additional burden for a struggling student. Remediation times could be set in that students would have a fixed number of days to restudy and retest. ${ }^{50}$ This time could be used for the other students to complete enrichment activities. Another alternative is optional midterms. These would allow those that need to re-test an opportunity to study and be tested and for the other students, maybe an opportunity to earn points towards summative assessments.

For enrichment activities it may be advantageous to pull in future course work that is related to a topic. First, this falls in line with competency-based education in that students can proceed at their own pace until they reach competency. By bringing some of the future work backwards, those students that excel can learn more quickly. As mentioned, extra credit may be used to incentivize completion early on. Alternatively, completion of enrichment activities could be used to lower thresholds on summative assessments.

Table 3 shows what a sample course may look like using the mastery learning model.

\section{Benefits and Potential Pitfalls}

Apoignant issue in education is disability (invisible and visible) and diversity, equity, and inclusion. The sentiment that everyone can learn is apparent in the Universal Design for Learning framework (UDL). UDL has 3 principle components: provide multiple means of representation (the "what" of learning"); provide multiple means of representation (the "how" of learning); and multiple means of engagement (the "why" of learning) ${ }^{51}$ The mastery learning approach addresses all 3 principles. For example, mastery learning addresses the "multiple means principle" because it typically has multiple ways for students to acquire the required knowledge, skills and attitudes. Consistent with "multiple means of engagement", if a student does not acquire mastery in the first attempt, the corrective activities will address a different method of instruction, Similarly, the various approaches to learning, the corrective activities, the enrichment activities and the multiple chances and formats to demonstrate mastery capture all 3 principles. Because the UDL framework proceeded the original work within the mastery model, there are scholarly opportunities to merge the two frameworks.

A concern with any course format is the issue of faculty workload. In the mastery model there should be feedback, multiple versions of assessment, and overall tracking and with this comes the issue of workload. For feedback, there are numerous opportunities to automate feedback through learning management systems and other educational software (eg, ExamSoft). Assessments are linked to outcomes and reports generated on success of moving towards that desired outcome. While this may take upfront work, it is reusable year to year. For multiple versions of assessments, this again may be upfront work but reusable year to year. There is less concern about assessment security because the goal is primarily for feedback and drive learning. The exception would be the assessments aimed at more summative assessment may require yearly updating but this practice can be faculty-dependent.

Another concern may be the impact of one course designed with a mastery learning framework or multiple courses in each semester and the student workload. Currently, pharmacy curriculum may have multiple courses that are team-based learning or flipped which may have similar dilemmas - how to manage student time. For example, one university has testing curriculum wide meaning each course is assessed with one test every few weeks and the feedback and corrective activities then provided. ${ }^{50}$ The coordinated effort can help alleviate the additional work that may occur with 
several courses running independently. In Schools of Medicine, there are accreditation standards about monitoring student time. With appropriate oversight and guidance, setting limits on required (eg, preclass activities) and non-required elements (eg, general study) may be helpful in managing multiple classes.

\section{CONCLUSION}

Mastery learning has shown improved learning outcomes compared to more traditional methods of learning. According to current understanding of learning theories, mastery learning also has a strong theoretical basis. This framework may be a viable approach to address the desire for competency-based education and more work is needed on four fronts. The first is how to implement mastery learning curriculum wide. Second, how does mastery learning compared to the current "engaged" or high structure instructional settings (eg, flipped classrooms or team-based learning). Third, how can mastery learning be used to better communicate standards and achievement to outside stakeholders. Fourth, how do we best optimize mastery learning given the current evidence on best practices in education.

\section{REFERENCES}

1. Frank JR, Snell L, Englander R, Holmboe ES, Collaborators I, on behalf of the IC. Implementing competencybased medical education: Moving forward. Med Teach. 2017;39(6):568-73.

2. Touchie $\mathrm{C}$, ten Cate $\mathrm{O}$. The promise, perils, problems and progress of competency-based medical education. Med Educ. 2016;50(1):93-100.

3. Guskey TR. Closing Achievement Gaps: Revisiting Benjamin S. Bloom's "Learning for Mastery". J Adv Acad. 2007;19(1):8-31.

4. $\quad$ Guskey TR. Implementing mastery learning. 2nd ed. Belmont, Calif.: Wadsworth Pub. Co.; 1997.

5. Mager RF. Preparing instructional objectives. Rev. 2nd ed. Belmont, Calif.: Pitman Management and Training; 1984.

6. Doran GT. There's a SMART Way to Write Management's Goals and Objectives. Vol 70: American Management Association; 1981:35-6.

7. Sekulich KM. Learning through Formative Feedback: A Review of the Literature. Phi Delta Kap. 2020;86(3):519.

8. Shute VJ. Focus on Formative Feedback. Rev Educ Res. 2008;78(1):153-89.

9. Block JH, Airasian PW. Mastery learning: theory and practice. New York,: Holt; 1971.

10. Biggs J. Enhancing Teaching through Constructive Alignment. Higher Educ. 1996;32(3):347-64.

11. Cohen SA. Instructional Alignment: Searching for a Magic Bullet. Educ Research. 1987;16(8):16-20.

12. van de Ridder JMM, Peters CMM, Stokking KM, de Ru JA, ten Cate OTJ. Framing of feedback impacts student's satisfaction, self-efficacy and performance. Adv Health Sci Educ. 2015;20(3):803-16.

13. Van De Ridder JMM, Stokking KM, McGaghie WC, Ten Cate OTJ. What is feedback in clinical education? Med Educ. 2008;42(2):189-97.

14. Ellaway RH, Chou CL, Kalet AL. Situating Remediation: Accommodating Success and Failure in Medical Education Systems. Acad Med. 2018;93(3):391-8.

15. Kalet A, Guerrasio J, Chou CL. Twelve tips for developing and maintaining a remediation program in medical education. Med Teach. 2016;38(8):787-92.

16. Deddeh H, Main E, Fulkerson SR. Eight Steps to Meaningful Grading. Phi Delta Kap. 2010;91(7):53-8.

17. Hooper J, Cowell R. Standards-Based Grading: History Adjusted True Score. Educ Assess. 2014;19(1):58-76.

18. Zimmerman T. Grading for Understanding - Standards-Based Grading. Physic Teach. 2017;55(1):47-50.

19. Guskey TR, Pigott TD. Research on Group-Based Mastery Learning Programs: A Meta-Analysis. J Educ Res. 1988;81(4):197-216.

20. Kulik C-LC. Effectiveness of Mastery Learning Programs: A Meta-Analysis. Rev Educ Res. 1990;60(2):265-99.

21. Marshall LD. Effects of mastery learning grading policies on student achievement, ProQuest Dissertations Publishing; 2016.

22. McGaghie WC, Issenberg SB, Barsuk JH, Wayne DB. A critical review of simulation-based mastery learning with translational outcomes. Med Educ. 2014;48(4):375-85.

23. Whiting B, Render GF. Cognitive and Affective Outcomes of Mastery Learning: A Review of Sixteen Semesters. Clearing House. 1987;60(6):276-80.

24. Kulik JA, Kulik C-1C, Cohen PA. A meta-analysis of outcome studies of Keller's personalized system of instruction. Am Psychologist. 1979;34(4):307-18.

25. Howard JL, Bureau J, Guay F, Chong JXY, Ryan RM. Student Motivation and Associated Outcomes: A MetaAnalysis From Self-Determination Theory. Persp Psychol Sci. 2021:1745691620966789-. 
26. Luria E, Shalom M, Levy DA. Cognitive Neuroscience Perspectives on Motivation and Learning: Revisiting SelfDetermination Theory. Mind Brain Educ. 2021;15(1):5-17.

27. Martin AJ, Elliot AJ. The role of personal best (PB) goal setting in students' academic achievement gains. Learn Individ Diff. 2016;45:222-7.

28. Morisano D, Hirsh JB, Peterson JB, Pihl RO, Shore BM. Setting, Elaborating, and Reflecting on Personal Goals Improves Academic Performance. J Appl Psychol. 2010;95(2):255-64.

29. Barenberg J, Dutke $\mathrm{S}$. Testing and metacognition: retrieval practise effects on metacognitive monitoring in learning from text. Memory 2019;27(3):269-79.

30. Yang BW, Razo J, Persky AM. Using testing as a learning tool. Am J Pharm Educ. 2019;83(9):1862-72.

31. Marsh EJ, Eliseev ED. Correcting Student Errors and Misconceptions. In: Dunlosky J, ed. The Cambridge handbook of cognition and education. New York: Cambridge University Press; 2019:417-59.

32. Dunlosky J, Rawson KA. Practice Tests, Spaced Practice, and Successive Relearning: Tips for Classroom Use and for Guiding Students' Learning. Schol Teach Learn Psychol. 2015;1(1):72-8.

33. Rawson KA, Dunlosky J, Sciartelli SM. The Power of Successive Relearning: Improving Performance on Course Exams and Long-Term Retention. Educ Psychol Rev. 2013;25(4):523-48.

34. Vaughn KE, Dunlosky J, Rawson KA. Effects of successive relearning on recall: Does relearning override the effects of initial learning criterion? Mem Cog. 2016;44(6):897-909.

35. Dunlosky J, O'Brien A. The power of successive relearning and how to implement it with fidelity using pencil and paper and web-based programs. Schol Teach Learn Psychol. 2020.

36. McGaghie WC. When I say . mastery learning. Med Educ. 2015;49(6):558-9.

37. Hattan C, Singer LM, Loughlin S, Alexander PA. Prior Knowledge Activation in Design and in Practice. Lit Res. 2015;64(1):478.

38. Witherby AE, Carpenter SK. The rich-get-richer effect: Prior knowledge predicts new learning of domainrelevant information. J Exp Psychol Learn Mem Cog. 2021.

39. Butler AC, Black-Maier AC, Campbell K, Marsh EJ, Persky AM. Regaining access to marginal knowledge in a classroom setting. Appl Cog Psychol. 2020;34(5):1005-12.

40. Schimmelfing LC, Persky AM. Activating prior knowledge using multiple-choice question distractors. Med Educ. 2020;54(10):925-31.

41. Wetzels SAJ, Kester L, van Merriënboer JJG. Adapting prior knowledge activation: Mobilisation, perspective taking, and learners' prior knowledge. Comp Hum Behav. 2011;27(1):16-21.

42. Murad MH, Coto-Yglesias F, Varkey P, Prokop LJ, Murad AL. The effectiveness of self-directed learning in health professions education: a systematic review: Effectiveness of self-directed learning. Med Educ. 2010;44(11):1057-68.

43. Kyndt E, Raes E, Lismont B, Timmers F, Cascallar E, Dochy F. A meta-analysis of the effects of face-to-face cooperative learning. Do recent studies falsify or verify earlier findings? Educ Res Rev. 2013;10:133-49.

44. Balta N, Michinov N, Balyimez S, Ayaz MF. A meta-analysis of the effect of Peer Instruction on learning gain: Identification of informational and cultural moderators. Int J Educ Res. 2017;86:66-77.

45. Coderre S, Woloschuk W, McLaughlin K. Twelve tips for blueprinting. Med Teach. 2009;31(4):322-4.

46. van de Ridder JMM, Peters CMM, Stokking KM, de Ru JA, ten Cate OTJ. Framing of feedback impacts student's satisfaction, self-efficacy and performance. Adv Health Sci Educ. 2014;20(3):803-16.

47. Halim A, Mahzum E, Yacob M, Irwandi I, Halim L. The impact of narrative feedback, e-learning modules and realistic video and the reduction of misconception. Educ Sci. 2021;11(4):158.

48. Lachner A, Jacob L, Hoogerheide V. Learning by writing explanations: Is explaining to a fictitious student more effective than self-explaining? Learn Instruct. 2021;74:101438.

49. Kowalski P, Taylor AK. Reducing Students' Misconceptions With Refutational Teaching: For Long-Term Retention, Comprehension Matters. Schol Teach Learn Psychol. 2017;3(2):90-100.

50. Bray BS, Remsberg CM, Robinson JD, et al. Implementation and preliminary evaluation of an honourssatisfactory-fail competency-based assessment model in a doctor of pharmacy programme. Pharm Educ. 2017;17(1):143-53.

51. CAST. Universal Design for Learning (UDL) Guidelines: Version 2. Wakefield, MA 2011. 
Figure 1. Depiction of the mastery model and its relation to success of the learner. ${ }^{4,14}$

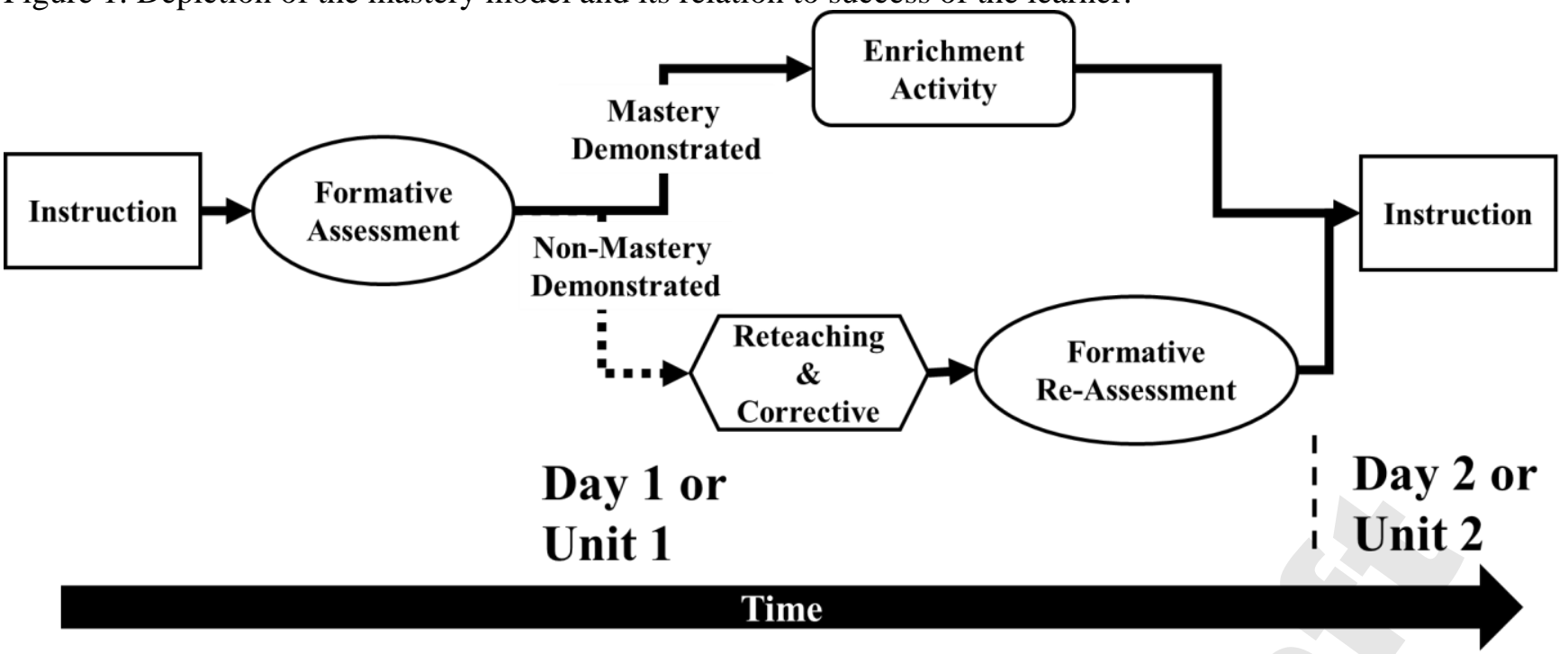

Figure 2. Example of a mastery model for a modern curriculum
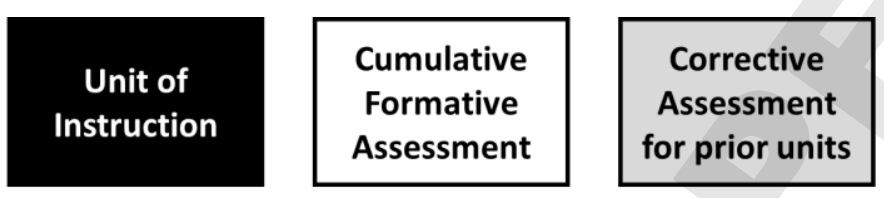

Summative
Assessment

\begin{tabular}{|c|c|c|c|c|c|c|c|c|c|c|c|c|}
$\begin{array}{c}\text { Unit } \\
1\end{array}$ & $\begin{array}{c}\text { Unit } \\
1\end{array}$ & $\begin{array}{c}\text { Unit } \\
2\end{array}$ & $\begin{array}{c}\text { Unit } \\
2\end{array}$ & $\begin{array}{c}\text { Unit } \\
3\end{array}$ & $\begin{array}{c}\text { Unit } \\
3\end{array}$ & $\begin{array}{c}\text { Unit } \\
1-3\end{array}$ & $\begin{array}{c}\text { Unit } \\
4\end{array}$ & $\begin{array}{c}\text { Unit } \\
4\end{array}$ & $\begin{array}{c}\text { Unit } \\
5\end{array}$ & $\begin{array}{c}\text { Unit } \\
5\end{array}$ & $\begin{array}{c}\text { Unit } \\
4-5\end{array}$ & $\begin{array}{c}\text { Unit } \\
1-5\end{array}$ \\
\hline
\end{tabular}


Table 1. Example of Assessment Blueprint based on the impact and frequency of the topic with spacing of topics to help optimize learning (based on reference ${ }^{45}$ )

\section{Formative Assessments (Number of Items)}

\begin{tabular}{|c|c|c|c|c|c|c|c|c|c|c|c|c|c|c|c|}
\hline Topic & $\begin{array}{l}\text { Impact } \\
\text { (I) }\end{array}$ & $\begin{array}{l}\text { Frequency } \\
\text { (F) }\end{array}$ & $\mathbf{I x F}$ & Weight & 1 & 2 & 3 & 4 & 5 & 6 & 7 & 8 & 9 & $\begin{array}{c}\text { Examination } \\
\text { (number of items) }\end{array}$ & Total \\
\hline 1 & 2 & 2 & 4 & 0.11 & 8 & 3 & & 1 & & & 1 & & & 6 & $19(11 \%)$ \\
\hline 2 & 1 & 3 & 3 & 0.09 & & 6 & 3 & & & & 1 & & & 4 & $15(9 \%)$ \\
\hline 3 & 3 & 2 & 6 & 0.17 & & & 10 & 3 & 2 & 2 & 1 & 1 & 1 & 9 & $29(18 \%)$ \\
\hline 4 & 3 & 3 & 9 & 0.26 & & & & 11 & 3 & 3 & 3 & 3 & 3 & 13 & $39(24 \%)$ \\
\hline 5 & 2 & 1 & 2 & 0.06 & & & & & 5 & 1 & & 1 & & 3 & $10(6 \%)$ \\
\hline 6 & 2 & 2 & 4 & 0.11 & & & & & & 8 & 3 & & 2 & 6 & $19(11 \%)$ \\
\hline 7 & 1 & 2 & 2 & 0.06 & & & & & & & 5 & 2 & & 3 & $10(6 \%)$ \\
\hline 8 & 3 & 1 & 3 & 0.09 & & & & & & & & 7 & 3 & 4 & $15(9 \%)$ \\
\hline 9 & 2 & 1 & 2 & 0.05 & & & & & & & & & 7 & 3 & $10(6 \%)$ \\
\hline & & Total & 35 & 1 & 8 & 9 & 13 & 15 & 10 & 14 & 14 & 14 & 16 & 50 & \\
\hline
\end{tabular}

Impact: 1: non-urgent/smaller importance; 2 : serious / important; 3: urgent/very important Frequency: 1: rare/less frequent; 2 : occasional; 3 :frequent/very common.

IxF: product of impact and frequency

Weight: relative weighting of topic as a proportion of total questions. 
Mastery Area

Learning Outcomes

Acquisition

Assessment

Corrective

Enrichment

\section{Recommendation}

Use the Mager model for learning outcomes that include the level of desired mastery, the format and context of the assessment and the desired outcome

Use current best practices which may include activation of prior knowledge, selfpaced learning, peer-to-peer instruction, retrieval practice, and feedback

Aligned with learning objectives, these can be multiple choice or open-ended. Regardless, feedback should be provided. These assessments should also be cumulative to space out practice and optimize retrieval.

Corrective activities need to be in a different instructional format than original instruction.

These should be clinically relevant and maybe preview future curricular content. Incentives can be used to motivate students to complete them, especially early in the course. 
Table 3. Example of mastery learning for a foundational pharmacokinetics course.

\begin{tabular}{|c|c|c|c|c|c|}
\hline Unit & Topic & Acquisition & Assessment & Corrective & Enrichment \\
\hline 1 & $\begin{array}{l}\text { Single Dose } \\
\text { Intravenous Bolus } \\
\text { Kinetics }\end{array}$ & $\begin{array}{l}\text { 1. } \begin{array}{l}\text { Preclass } \\
\text { Reading }+ \\
\text { Activity }\end{array}\end{array}$ & $\begin{array}{l}\text { 1. Formative } \\
\text { Assesment } \\
\text { using final }\end{array}$ & $\begin{array}{l}\text { 1. Formative } \\
\text { Assessment } \\
\text { Autopsy }\end{array}$ & Dosing Lithium \\
\hline 2 & $\begin{array}{l}\text { Single Dose } \\
\text { Extravascular Dose } \\
\text { Kinetics }\end{array}$ & $\begin{array}{l}\text { 2. Activity } \\
\text { review } \\
\text { (peer }\end{array}$ & $\begin{array}{l}\text { exam-like } \\
\text { questions. } \\
\text { Threshold }\end{array}$ & & $\begin{array}{l}\text { Dosing in } \\
\text { Obesity }\end{array}$ \\
\hline 3 & $\begin{array}{l}\text { Continuous } \\
\text { Infusions }\end{array}$ & $\begin{array}{l}\text { instruction) } \\
\text { 3. Debrief }\end{array}$ & $\begin{array}{l}70 \% \text { to } \\
\text { pass }\end{array}$ & & Warfarin Dosing \\
\hline 4 & Multiple Dosing & $\begin{array}{ll}\text { 4. } & \text { Homework } \\
\text { 5. } & \text { Debrief } \\
\text { Homework } \\
\text { (feedback) }\end{array}$ & & & $\begin{array}{l}\text { Aminoglycoside } \\
\text { Dosing }\end{array}$ \\
\hline & Midterm 1 & $\begin{array}{l}\text { Optional. If For } \\
\text { of the corrective }\end{array}$ & $\begin{array}{l}\text { lative Assessmen } \\
\text { activities for Uni }\end{array}$ & $\begin{array}{l}<70 \% \text {, midterm } \mathrm{s} \\
1-4 . \text { Need } 75 \% \mathrm{ts}\end{array}$ & $\begin{array}{l}\text { ves as the retest } \\
\text { ass }\end{array}$ \\
\hline 5 & Hepatic Clearance & Same as above & $\begin{array}{l}\text { Formative } \\
\text { Assesment }\end{array}$ & $\begin{array}{l}\text { Formative } \\
\text { Assessment }\end{array}$ & $\begin{array}{l}\text { Dosing in } \\
\text { Geriatrics }\end{array}$ \\
\hline 6 & Renal Clearance & & $\begin{array}{l}\text { using final } \\
\text { exam-like }\end{array}$ & Autopsy & $\begin{array}{l}\text { Dosing in } \\
\text { Neonates }\end{array}$ \\
\hline 7 & $\begin{array}{l}\text { Multicompartment } \\
\text { Behavior }\end{array}$ & & $\begin{array}{l}\text { questions. } \\
\text { Threshold } 70 \%\end{array}$ & & $\begin{array}{l}\text { Dosing } \\
\text { vancomycin }\end{array}$ \\
\hline 8 & $\begin{array}{l}\text { Nonlinear } \\
\text { Pharmacokinetics }\end{array}$ & & to pass & & $\begin{array}{l}\text { Dosing in Renal } \\
\text { Dysfunction }\end{array}$ \\
\hline 9 & Pharmacodynamics & $\begin{array}{l}\text { Optional. If Forl } \\
\text { of the corrective }\end{array}$ & $\begin{array}{l}\text { ative Assessmen } \\
\text { activities for Uni }\end{array}$ & $\begin{array}{l}70 \%, \text { midterm s } \\
5-9 . \text { Need } 75 \% \text { t }\end{array}$ & $\begin{array}{l}\text { Antidepressant } \\
\text { Dosing } \\
\text { jes as the retest } \\
\text { ass. }\end{array}$ \\
\hline 10 & $\begin{array}{l}\text { Integration and } \\
\text { Review } \\
\text { Practice Assessment }\end{array}$ & \multicolumn{4}{|c|}{$\begin{array}{l}\text { Required. Formative assessment to help students prepare for final exam } \\
\text { and may serve as } 3^{\text {rd }} \text { retest (if needed) Need } 80 \% \text { to pass }\end{array}$} \\
\hline & $\begin{array}{l}\text { Summative } \\
\text { Assessment }\end{array}$ & \multicolumn{4}{|c|}{ Required: Graded for High Pass (>90\%), Pass $(>75 \%)$ and Fail $(<75 \%)$} \\
\hline
\end{tabular}

